\title{
Support for Students with Hidden Disabilities in Universities: A Case Study
}

Donna Couzens (The University of Queensland), Shiralee Poed (The University of Melbourne), Mika Kataoka (Kagoshima University), Alicia Brandon (Landmark College), Judy Hartley (Griffith University) and Deb Keen (Australian Catholic University).

Key words: Higher Education, Learning disability, Universal Design for Learning, ADHD, Autism, Adult Learning

Authors' note. Data reported in this paper were collected as part of a larger international study comparing the establishment of universal design for students in higher education. This research was funded by an international research grant from the Heiwa Nakajima Foundation (inc). Project leader for the international project was Associate Professor Mika Kataoka, from Kagoshima University. We also acknowledge the work of Munehisa Yoshitoshi PhD.

(Okayama University) for his collaboration and recording of the interviews used in this paper. Finally we would like to thank the staff and students who shared their stories for this research.

Corresponding Author: Donna Couzens, PhD. School of Social Work and Human Services, The University of Queensland. Email d.couzens@uq.edu.au 
Support for students with hidden disabilities. $\quad 2$ 


\begin{abstract}
More students with disabilities are accessing the tertiary sector with many disabilities not easily observed (or hidden), as there are no physical indicators. These 'hidden' disabilities affect a variety of cognitive processes and may be developmental or acquired. To ensure students with hidden disabilities can enroll, engage in and benefit from tertiary education, universities generally provide a range of supports. Typically these supports and any reasonable adjustments are negotiated with students taking into account a number of factors including, where available, any supporting documentation that they might be able to provide. This case study reports efforts within one large Australian university to support higher education students with hidden disabilities on campus. Perceptions on the use of and barriers to support available were collected from seven undergraduate students who self-identified as having hidden disabilities, and eight support staff. Results indicated that students found their informal networks to be their most effective supports closely followed by clear, caring and flexible lecturers and tutors. There were mixed positive and negative perceptions reported on the universal and disability specific supports available. Implications and future research directions are discussed.
\end{abstract}




\section{Support for Students with Hidden Disabilities in Universities: A Case Study}

Across institutes of higher education there is increasing emphasis on enrolling, supporting and retaining a diverse student population and working to promote the engagement of these students within their chosen field of study (see, for example, Kuh, Kinzie, Schuh, \& Whitt, 2005; Perdigones, Garcia, Valino, \& Raposo, 2009). Universities worldwide are seeking to attain high academic standards while catering for an increasingly diverse student population (see, for example, Haggis, 2006; J. R. Kirby, Silvestri, Allingham, Parrila, \& La Fave, 2008; Tinklin, Riddell, \& Wilson, 2004). This focus on equity in quality learning bodes well for many students with disabilities, however, a number of barriers continue to prevent the realisation of these goals for many students in large universities and these will be considered in this paper via a case study involving an Australian university.

Unrecognised by many university staff, but increasing in number in the university sector, are students with hidden disabilities. Hidden disabilities can be developmental or acquired; hidden as they rarely have a physical presentation but rather affect a range of cognitive processes. Reference is made to some of these disabilities in this paper, including specific learning disability (LD), attentiondeficit/hyperactivity disorder (ADHD) and autism spectrum disorder (ASD).

In higher education, there is variation in the reported number of students with hidden disabilities. This variation may be attributed to the requirement at some universities for students to have their disability verified (recently diagnosed by the medical profession) where at other universities all students who choose to disclose their disability for the purpose of accessing accommodations ${ }^{1}$ at the university (with or without supporting documentation) are reported. In the United Kingdom hidden

\footnotetext{
${ }^{1}$ In Australia the term adjustments may be used in place of accommodations
} 
disabilities account for the vast majority of students disclosing a disability as they enter higher education (Goode, 2007). By contrast, in Australia numbers are more conservative, perhaps due to differences in defining groups (Smith, Carroll, \& Elkins, 1999). Smith, et al. (1999) warn against comparing data to that found in other countries as systems of assessment, diagnostic categories and service provision can change the meaning of data from country to country. The high incidence and hidden nature of such disabilities, however, increases the importance of developing awareness of these student's requirements across the university sector.

Harrison, Nichols, and Larochette (2009) emphasise the importance of comprehensive assessments for assisting students with learning disabilities to understand the fundamental reasons for their difficulties, providing information that will assist the student to self-advocate so that their specific needs can be met, and offering detailed suggestions regarding the most effective ways to address issues. The authors noted, however, that for students in their Canadian sample, the majority of assessment reports were inadequate even for basic diagnostic purposes.

While diverse learners may require accommodation or modification within the higher education context, there are important equity questions around the value of resourcing assessments which outline the nature of a student's difficulties and how these may impact them in higher education. This is especially true for students who may prefer a less intrusive and more normalising approach to their learning differences (e.g. Rasher, 2008). Students with learning difficulties may perceive community attitudes to the difficulties more negatively than students without learning difficulties (May \& Stone, 2010). It seems that many students in higher education do not seek detailed assessment to determine the cause or impact of a possible hidden disability when they experience learning difficulties (e.g. Ryan, 2007). Some may 
even have developed the desire to closet early difficulties at all costs due to early stigmatising experiences (Hartman-Hall \& Haaga, 2002; Ryan, 2007; Woodcock \& Vialle, 2011). The reasons for not seeking specialist assessment in adulthood are complex but can include not wanting to be 'treated', or seeing their learning differences as integral to their personality and not needing to be 'fixed,' or not recognizing any benefits from accessing a diagnostic assessment (see, for example, Prowse, 2009; Rasher, 2008).

The Australian Disability Standards for Education 2005 (Commonwealth of Australia, 2006) place onus on education institutions to proactively accommodate students with a disability (Dickson, 2007). However, if a student does not reveal an impairment "in sufficient detail to allow an institution to respond to it" the institution is not obligated to make adjustments under the discrimination act (Dickson). To further complicate matters, Australian higher education providers are eligible for Commonwealth rebates for expenditure on supporting students with disabilities, but only where there is evidence of medical or specialist documentation of the disability and supports required (DEEWR, 2010).

Equity issues arising in relation to requirements for verification of the nature of their difficulty, as well as comprehensive assessments to access required supports, represents an important consideration as universities seek to boost access and participation of groups who are underrepresented in higher education (Commonwealth of Australia, 2009). While some students may access comprehensive assessments informing required adjustments, other students may be unable or choose not to access this type of specialised assessment. While Australian universities can safely assume that there are greater numbers of students with learning disabilities than officially pass through their disability offices, the task of understanding the support 
requirements of this heterogeneous group of students, in regard to their learning strengths, weaknesses, experiences and resources, is complex. This case study represents an examination of one university's approach toward more equitable and inclusive supports for students with a range of learning difficulties.

The aim of the case study was to identify the strengths, gaps and opportunities from an Australian university's approach to support that combined disability specific and universal strategies to provide effective higher education experiences to students with diverse requirements. The investigation was not specific to students with documentation supporting their self-disclosed difficulties and in this way expands current research to include the perceptions and behaviours of students self-identifying as having learning and/or planning and organisational difficulties that may not have been verified.

First we describe some general examples of student groups with hidden disabilities who require supports in Australian universities. Second we describe the support strategies that were being implemented by the university to target these types of issues, at the time of the study. Finally we provide interview data from a small group of students and staff at the university who commented on their own experiences of the supports available and used by students at the time of the study.

\section{Learning Requirements Related to Learning Disability}

Every student's developmental and experiential pathways differ, and issues faced by individual students vary both within and between disability specific groups. Over time, students develop their own mechanisms for; understanding the impact of their disability on their learning, approaching tasks, advocating for and accessing support, and regulating their behaviour in different contexts. Common themes however, have arisen in the literature for students generally across the various 
disability groups. These themes include; being misunderstood by university staff, a fear of stigma in relation to requesting accommodations and additional time, and the intense stress that can be associated with specific tasks relative to students without the disability (see, for example, Denhart, 2008).

For higher education students with a specific learning disability (LD) in the area of reading (dyslexia), understanding complex text, taking lecture notes, writing essays, synthesising course material, and time management may all cause difficulties and anxieties (J. R. Kirby, et al., 2008). Kirby and colleagues found higher education students with dyslexia made greater use of study aids and time management principles while they used fewer strategies for selecting main ideas and taking exams. Students in university programs, but not in vocational programs, tended to use more deep approaches to study than their counterparts without dyslexia. Deep approaches are marked by a learner's intrinsic interest and engagement in course tasks, whereby they are seeking meaning and have been contrasted with surface approaches to learning, which are often motivated by the goal of avoiding failure and reproducing rather than understanding content (see, Baeten, Kyndt, Struyven, \& Dochy, 2010).

Other learning disabilities such as developmental coordination disorder (apraxia) present different patterns of difficulty for higher education students, including legibility and speed of handwriting, and attention difficulties (A. Kirby, Sugden, Beveridge, \& Edwards, 2008). Students, regardless of disability group, report different patterns of learning strengths (A. Kirby, et al.). The researchers found that subgroups of students within both the reading disability and coordination disorder groups, differentially reported either communicating and public speaking or organisational and time management as their academic strengths lending support to 
the notion that flexible supports accessible to individuals may be more efficacious than programs targeting specific disability groups (A. Kirby, et al.).

Attention-deficit/hyperactivity disorder (ADHD) is another, well publicised but poorly understood disability, diagnosed on the basis of inattentive and/or hyperactive and impulsive behaviour (American Psychiatric Association, 2000). Three and a half percent of the adult population, on average, have been estimated to have ADHD with mood and substance use issues commonly comorbid and a major trigger for accessing medical support within this group (Fayyad et al., 2007). As for students with LD, compensatory behaviours, developed over the years and enabling them to enter higher education, frequently determine their later strengths and difficulties. Sarah Rasher, an academic at the University of Connecticut who selfidentified as having ADHD, presented some of her own independent learning strategies that assisted her to attend to learning tasks while satisfying her continuing need for stimulating activity and movement. Rasher (2008) described how she kept herself over-extended to keep busy and avoid boredom in her different classes, and the benefits for her of independent study in special areas of interest. She highlighted her adoption of deep approaches to learning and her strengths in conceptualising topics broadly to her academic success (Rasher). Deep and purposeful learning is a universal approach supporting academic success across the diverse range of university students. “The simple goal of staying engaged may not compensate for all or even most cases of ADHD, but it seems to work for me and for my students. It's not just the fidgety kids who want a reason to sit still” (Rasher, para. 14).

While approximately $50 \%$ of adults with ADHD have been estimated to access medical treatment in the USA, the proportion of those with ADHD symptomatology, assessed using the same tool, who accessed medical treatment in 
other countries was significantly lower (20 to 23\% in Belgium, Netherlands and Spain, 10 to $12 \%$ in Columbia, France, Germany and Mexico and only 1.1\% in Lebanon) (Fayyad, et al., 2007). Australia similarly has very low rates of formal diagnosis for adults with symptoms of ADHD (e.g. Kaye, Darke, \& Torok, 2013).

Other heterogeneous populations within higher education settings include students with autism spectrum disorders (ASDs) such as Asperger's syndrome and high functioning autism. Students with an ASD are diagnosed as a result of early and ongoing difficulties with social interaction, social communication, and repetitive behaviours and interests (American Psychiatric Association, 2000). Sustained attention and attention to detail necessary for successful study in higher education is often identified as a strength for students with an ASD. These students, however, can experience difficulty moving beyond the detail they are studying to see the big picture (Happé, 2000). Students with an ASD have also been reported to have difficulty selfinitiating the use of learning and memory strategies they may have learnt, such as organising information, associating new information with known information and using rehearsal strategies, relative to their typically developing peers (Bebko \& Ricciuti, 2000). Bebko and Ricciuti suggested that for students with an ASD "the hows of learning must be taught with an emphasis at least equal to, if not greater than, the whats” (p. 318). Episodic memory may also be affected for some students (Benshalom, 2003; Hare, Mellor, \& Azmi, 2007) including poor recollection of events and places (Bowler, Gardiner, \& Grice, 2000).

The most salient barriers for students with an ASD, reported by higher education staff, relate to difficulties regulating emotions. Some students experience high levels of stress in social interactions, poor planning and organisation for everyday tasks of daily living and poor skills accessing assistance (see MacLeod \& 
Green, 2009). As social situations represent a major source of stress for some students with ASDs resultant avoidance can result in social isolation. Isolation in the higher education setting results in reduced sources of assistance and clarification and often contributes to mental health problems. MacLeod and Green suggested that holistic social support packages might be necessary for these students and those experiencing similar challenges, to navigate the social demands of university life. MacLeod and Green recommended these supports include personal mentors and individualised and targeted development of social support networks.

Unusually high or low sensitivity to different environmental situations have also been reported in relation to many individuals with autism spectrum disorders (Crane, Goddard, \& Pring, 2009). Noise, crowds, visual clutter, tactile and other sensory intrusions may cause stress for some, while the lack of responsiveness to the behaviours of fellow students or to external stimuli may also alienate these students from their peers. Learning disabilities have frequently been reported to occur in combination compounding difficulties that may be associated with a single disorder. Developmental apraxia (motor coordination disorder), for example often present difficulties for students with an ASD (Green et al., 2002).

While it may appear, from the discussion above, that students with hidden disabilities are able to be assessed and sorted neatly into a disability-specific category for service provision, the reality is that there are many conditions that can affect cognitive processes (e.g. Boone et al., 2001; Laskera, Mazzocco, \& Zee, 2007; Prevatt, Welles, Li, \& Proctor, 2010), diagnoses frequently overlap (Fayyad, et al., 2007; Landerl \& Moll, 2010), and people attending medical appointments for these kinds of difficulties may receive conflicting and changing reports over time and from different practitioners (see, for example, Gupta, 2010; Robinson, 2002). Two formal 
approaches to support are possible when addressing the needs of these diverse learners: (a) strategies and supports may be universally offered to all students in the university or college or (b) differentiated, disability specific approaches may be provided to specific groups or individuals. Disability specific approaches may rely on students providing documentation on their disability and may therefore emphasise the difference of some students while at the same time neglecting cognitive differences of students who cannot or do not want to go through the processes required to attain suitable documentation. The university in this case study provided a combination of both approaches.

\section{The Case Study}

University $\mathrm{X}$ is a medium sized, Australian institution offering undergraduate, postgraduate and research programs across a broad range of disciplines. The university had around 40,000 students in total at the time of the study with approximately 15,000 to 16,000 new students commencing each year. Of the commencing students approximately 350 students self-identified as having a disability on entering the university each year (2008 figures, from the Department of Education Employment and Workplace Relations, 2008). Importantly, not all of these students sought support from the Disabilities Service and there were students who did not selfidentify when they entered the university who later sought support from the service. Over one third of the students who accessed the university's Disabilities Service did not identify as having a disability on their enrollment forms, and approximately one quarter of students who sought support did not provide appropriate documentation at their initial interview with the Disabilities Service (personal communication with the Manager, Equity at University X, 23 November, 2011). 


\section{Disability Support Services}

A range of supports were offered to students with disabilities, enrolled at University X, through the Disabilities Service. This element both maintained some disability specific focus, however, the primary approach was to focus on the development of systems supporting higher learning across the diverse range of learners. The approach differed from disability specific approaches (C. P. Smith, 2007) such as the employment of 'dyslexia advisors’ (see, for example, Ingram, Pianu, \& Welsh, 2007). Of interest, is whether university wide approaches are successful in supporting access, retention, engagement and ultimately facilitating success for students who have a range of hidden disabilities.

The Disabilities Service was comprised of a Manager, Student Equity and 3.6 full-time equivalent Disability Service Officers (DSOs). Each DSO was responsible for the coordination of services across one or two of the university's campuses, and also had specific cross-campus co-ordination responsibilities, such as whole-ofuniversity peer note-taking co-ordination or assistive technology responsibilities. Individual services were provided to students who had disclosed a verified disability, generally making contact with their DSO on a semester basis, but more frequently when required, to discuss their progress and identify learning barriers. The role of the DSO was to monitor performance of the university in relation to individual students and to co-ordinate services and new initiatives across the university and in collaboration with community organisations.

The stated philosophy of the Disabilities Service (DS) was to advocate for a system rather than advocating for individual students. The DS took both a proactive approach to identifying activities that would increase the intake and retention of students with disabilities as well as identifying areas of concern as they arose for 
students who accessed the service. More broadly, through individual supports offered to students, barriers within the system were identified and, where possible, addressed. The service was based on a 'student lifecycle model' with proactive programs established to support the different aspects of the student lifecycle. Programs were developed and refined to target transition of students with disabilities into the university, specific supports during their first year at university, the development of self-advocacy and self-management across their time at the university, and transition from university to employment.

In addition to preparatory programmes the university provided two learning support services one for students generally who sought assistance with academic skills and writing, and the other for finer grained assistance with sentence formation and grammar. Initially the finer tuned ‘English help’ was only available to students from cultural and linguistic backgrounds other than English and later became available to any student who was seeking fundamental help with their writing. Students were able to choose their own combination of individual and/or group appointments when accessing these supports.

All services were systematically evaluated and individual student's requirements were reviewed and revised each semester. The DS promoted selfmanagement and self-advocacy of students receiving individual consultations by supporting or explicitly teaching these students to become increasingly responsible for arranging and accessing services they required. Special consideration arranged directly by the DSO typically involved alternative examination arrangements such as alternative venues, use of a laptop, rest breaks, additional time (approximately 10 to 15 minutes per hour) and timing where, for example, an impairment or medication impacted concentration at certain times of the day. Students were supported, however, 
to assume increasing responsibility for identifying and negotiating their own requirements over time. The skills of self-determination and self-management along with access to assistive technologies have been identified as fundamental in retention of students with disabilities in higher education (Getzel, 2008). Provision of assistive technology represented a differentiated support strategy coordinated by DS and provided to students on the basis of supporting documentation. Library staff were trained to support technology laboratories on each campus with use monitored by DS. Where possible, software was purchased as a multiple user licence providing more flexible access to students across centrally managed computers including laptops. Software included voice recognition, screen reading, and rule checking software.

\section{Universal Design Approaches}

In addition to tailored disability service provisions, a developing suite of universal design approaches were introduced across the university to enhance learning for diverse student groups. Universal Design for Learning (Rose and Meyer, 2002) has stimulated interest as it aims to provide inclusive environments for learning and engagement whereby all students can experience a range of choices for accessing, processing and demonstrating knowledge in their chosen area of specialisation. There were two areas where considerable resources were invested to improve the higher education experience across all students with diverse learning and social requirements which utilised universal design principles: innovations in blended learning and initiatives to enhance and refine first year connectedness and success at university.

\section{Blended learning}

Blended learning refers to the blending of technology based learning strategies alongside on-campus and distance learning experiences. Innovation at University X involved the provision of simulated lectures, and the creation of web-based course 
material, learning systems and discussion forums as well as videoed lecture capture in the larger theatres uploaded to course sites for general access. These integrated learning systems promise supports for a range of learning requirements providing independent and group study options, offering multiple ways of receiving lecture material, and self-paced viewing of course material. As with many university initiatives, successful application of these systems relied on individual lecturers to understand the technology, have the time to prepare and use it, and understand and agree to the principles of Universal Design these technologies may support. The technologies also rely on tutors and individual students to utilise the systems in ways that enrich and deepen learning through increased engagement rather than encouraging surface learning through passive viewing and simplistic application of course content.

Many of the differentiated support systems set up by DS may eventually be provided universally as technology becomes increasingly affordable and accessible. The long-standing peer note-taking program provided by DS incorporated the training of high achieving students to take high quality notes for students unable to produce their own high quality notes and while once highly utilised had begun to diminish in use. As web-based learning developed across the university, fewer students reported the need for the note-taking service as they accessed the more universally accessible PowerPoint slides and video of lectures on the course website. Sometimes however, it was necessary for the DSO to explicitly teach students attending individualised consultations, how to access the web-based materials.

\section{First year experience}

First year experience initiatives at University X targeted processes of learning and engagement in higher education and were designed to support all students to 
adopt scholarly and collaborative attitudes to university life. Programs were constantly reviewed and improved to develop skills, attitudes and social connections essential for academic success. First year initiatives were program-specific to ensure immersion and build links and understanding within the student's chosen specialisation. First year advisors were academic staff with the task of coordinating activities and facilitating links between individual students and the academic, social and personal supports available at the university.

First year initiatives aimed to universally promote engaged learners while facilitating self-advocacy and collaborative learning. Academic skills programs were provided to all students in areas including scheduling, study techniques, writing, and survival in the university setting. The universal approach to promote successful university learning and increase student retention was coordinated centrally but again relied on individuals and schools to understand the purpose and to drive the initiatives.

The first year experience was also enhanced through programs provided prior to students commencing at the university. Initiatives for transition into the university included organised visits both universally for schools and specific to students with disabilities across the final three years of secondary school. Programs for secondary school students offered experiences to enhance understanding of university expectations and also introduced students with disabilities to specific technologies and other support systems available in the university setting. Parents/caregivers and school staff were encouraged to attend the disability specific experience days and partner with the university to support successful transition by continuing to develop relevant readiness skills and attitudes for university life. Preparation aimed at building a sense of self-efficacy for independence, use of assistive technologies and learning 
aids may make the difference for retention of students with learning difficulties (Johnson, Zascavage, \& Gerber, 2008).

\section{Student Perceptions and Use of Supports}

As part of a larger international study of higher education experiences of students with learning disabilities and difficulties, a small sample of seven students (one male), who self-identified as experiencing learning or planning and organizational difficulties volunteered to be interviewed in response to a request via the university intranet. Three students had received special education programs at school. Two students reported learning difficulties once they reached tertiary level. Two student's difficulties were associated with a medically diagnosed illness and neither had been provided specific information about the associated learning difficulties they were experiencing. All students were enrolled in a teaching degree in early childhood, elementary, secondary or special education. Three students were mature age students and one student had changed programs due to academic difficulties in their previous program. Eight staff were also invited to be interviewed; a disability services officer, an equity officer, a combined first year advisor and lecturer, a coordinator of the first year advisors, two lecturers, a librarian and an information services officer. Two additional staff, who had been asked to participate, a lecturer and a writing support staff member were unavailable at the time of the interviews. Ethical clearance for the study was received from the review board of each university that participated in the international study. Written consent was received from all participants interviewed.

Interviews were scheduled during a one-week period to coincide with the international research team's visit to Australia. Interviews were semi structured with an emphasis on identifying personal perspectives on student use and barriers to 
effective use of supports in the university. Interviews covered a range of topics including early school experiences, social and general life experiences and attitudes to supports provided in their higher education setting. Questions for students, relevant to support use in higher education, included:

- Tell us about your learning strengths and learning difficulties.

- Have you received any learning support at university?

- Which supports do you find most useful at University X?

- Do you use the Disabilities Service? Why? Or Why not?

- Which supports do you find least useful at University X?

Questions for staff, relevant to student support, included:

- What do you think are the needs of students with learning difficulties at University $\mathrm{X}$ ?

- Have you experienced any issues in relation to working with/supporting students with learning difficulties?

Reported here are the explicit opinions provided by the interviewees about students' use of supports at University X and associated issues or barriers that arose relating to the effective use of the different supports that were available.

Students reported their informal support networks to be their most effective supports followed by informed, caring and clear lecturers and/or tutors. The universal initiatives relating to both first year programs and writing support initiatives received ambivalent responses, with both reported as highly valuable by some students and of little value by other students. Disability specific services were reported by one student to be essential to their success and well-being at the university. Other students did not access the Disabilities service and indicated that they perceived the service to be for students with more severe disabilities. Most frustration reported by students related to 
an inability to get adequately targeted support for their specific issues and poor dissemination of information on supports available at the times they were needed. The most common theme arising from both staff and student interviews involved the inconsistency of staff responses to students with difficulties. Resource limitations in relation to staffing one-to-one supports for English help, technology support and course specific support by lecturers and tutors were a feature of staff interviews. There were also important attitudinal differences toward learning difficulties generally in both staff and student responses and in students' emphasis or focus on deep learning verses assessment survival. A discussion of these interview topics are presented briefly.

\section{Capitalising on and strengthening informal support networks}

While the institutional responses of this university go a considerable way to address the needs of students with hidden disabilities in higher education the two most essential supports, informal networks and knowledgeable and caring teaching staff, remained relatively hit and miss for the students interviewed. All students indicated informal supports to be the most effective in supporting a variety of issues. A student, for example, described how her friends assisted her to understand directions in lectures;

I am one that, if someone explains something, I won't understand the directions...because she [a friend met at orientation] knows me so well, she can explain it to me or draw a picture or something...but there's a whole group of us that send emails and ask...we give and take equally. 
Another student reported how friends helped with her planning and organisational difficulties.

I found in the past year that the most successful strategy is becoming part of a study group... we give each other deadlines... we set up a reading schedule...you know that everyone else in the group is expecting your... summary of that chapter... that keeps you moving.

It was important that informal support networks understood a student’s experienced difficulties. One student, after naming family and friends as their most effective support, went on to say "particularly family because I've grown up having issues so mum and dad have always known and they've always given extra support...” When things were not good for a student, the lack of informal supports were cited as one major issue. Asked about his first year, one student responded, “Oh I didn’t like it at all. I had no friends. Well I had a few but no-one I was mates with...”

Methods for building on and strengthening peer and family networks in higher education represents an important area for supporting all students (see, for example, Bryan \& Simmons, 2009; Stokes, 2003) and may provide some of the most effective supports for students requiring 'safe' environments to openly discuss and problem solve in relation to hidden difficulties they may be facing.

\section{Use of universal support initiatives}

Student reports on the benefits of the universal supports were mixed, with some students finding every support "fantastic" and others finding them "boring” or choosing not to attend. One student reported "I go to orientation day every year because... it's an empowering day, they had a note taking course...how to complete an 
assignment, how to use a library...that was invaluable.” Negative reports from students related to disappointment that their specific issues were not addressed.

I’ve accessed learning support services, for getting my assignments checked and things like that. Which is great for structure but it's not something I have an issue with. It's the actual writing and the grammatical side that I find the issue.

Another student who accessed the generic writing help reported “...they were correcting stuff and I had no idea what they were doing." Another reported "Now that I'm a third and fourth year I don't use learning services at all. It's of no benefit to me anymore 'cause all that they're teaching is all about first years...” Sometimes the format of the support was reported to be unsuitable. One student noted about orientation, “...so much information is given to you all at the same time and you didn't know what was useful and what wasn't.” Another student did not attend orientation, commenting "we were probably the ones that were avoiding the group activities.” Sometimes communication was the major barrier to accessing supports.

I think that orientation probably didn't give me what I really needed... If the mentoring program was a bit more out there, I think I would probably have accessed that... in recent years I was asked to be a mentor, so I'm like "oh my god, there’s a mentor program!” So I think that would have been better.

Another student with learning disabilities and for whom English was a second language commented "it would be nice to know of the English help from first year 
instead of now...three years into my course... I know of a lot of students who aren't ESL that actually need the help as well...” It seems that information about this service and those eligible to access it was not reaching many students requiring these sorts of supports.

\section{Resource constraints}

At University $\mathrm{X}$ access to assistive technologies were restricted to students with documentation indicating a requirement for these types of support. Even for students with this documentation, as pointed out by one staff member, training in the use of the different technologies presented as an issue.

... in the library we provide access to the assistive technology... students are expected to come to the university with those skills or acquire them themselves... It is very difficult for them not only to learn this new university content but also to have to learn the technology that is going to help them... [in some situations] disability services have paid out of their funds for someone to come and do one-on-one training with them.

None of the students in the present study used assistive technologies. One student who had tried an early dictation package at school reported ... "I found that very difficult to use.”

Diagnostic processes are expensive for students financially, in time commitments, and have implications in regard to self-esteem and feelings of normality. None of the students interviewed had an assessment of any kind during their time at university as they did not perceive this need. 
While mentoring programs and study buddy networks were formally supported by university staff in first year, many students reported not finding out about these initiatives until it was too late and many students initiated networks for themselves later in their studies. One student reported that they had been close to leaving before finally establishing supportive ties in the university.

\section{Disabilities Service Use}

Most students reported that they would not consider using the Disabilities Service because they perceived this to be for students with greater needs. One student, reflecting on past school experiences, attributed her decision not to use the Disabilities Service directly to the trivialising of her difficulties at school “... because I was in mainstream, they didn't think I deserved to get it. They classified more severe cases and would focus on them first, then think about us, I guess less severe cases...”

Most staff relayed concerns that many students, despite significant issues, would not request help and that teaching staff sometimes initiated help for individual students. A lecturer, for example, reported “...one lass who had a breakdown just as she started the course...she didn't want to seek help...we got her in the end but it was delayed...”

The culture of the university was perceived as positive toward disability issues with one student relaying that her husband transferred from another university "because [University X] had been a lot more understanding and accepting.” There is ambiguity regarding 'caring' cultures in university. One lecturer reported "sometimes if students have done quite poorly on an assignment we will give them a pass but on the condition that they go to learning services and get some help.” While this approach may have some immediate appeal to lecturers in a difficult situation, it is 
counterproductive to “deep learning” and may contribute to a quick-fix assessment survival process with potential harm to the student's learning and to the university's reputation.

Students interviewed reported a range of approaches to their university learning, but for many, social and recreational aspects of life had been sacrificed as they pursued deep learning outcomes. One student, when asked “what do you spend most of your time doing?” Replied... “Study. I am not social at all. I have a small group of friends but ...when I'm here I'm working.” Some students reported being absorbed in their learning and the assessment as incidental. A pre-service teacher, for example, describing her learning motivation, said

... you think about kids you had on your prac... you read about case studies in textbooks... and the kids you are reading about are kids you know, they just jump up... and you're like, if I'd only known this much earlier... so how can we help that and then I go off on a tangent... and eventually go back to the assignment.

All students spent a lot of time with their study; some had developed deep approaches to learning, other students focussed on assessment and spent their time working to meet assessment criteria. Most reported working through a process to identify their own strategies that would get them through university, having experienced more formal support processes during their school years. One student commented that “...through high-school ...we did lots of trial and error with different programs and things...I did some tutoring and got extra help ...And then at uni it's just come through what I've learnt...” Another student reported 
I did a TAFE ${ }^{2}$ course between high school and university... I noticed that the visual, the doodling really worked for me... so I brought that with me to my university degree... highlighting... I colour co-ordinate... I went to tutoring and things like that when I was in primary school and highschool.

A third student recollected

... the first ten years I had been last in my class, I got lots of support and the teachers basically just ignored me in the end because they couldn't do anything with me... my writing is like a five year olds. I have very poor control... But I have to work on my writing if I'm going to be a teacher...

Maturation had reportedly alleviated most of the difficulties experienced by this third student during their schooling years, and they perceived their university difficulties to be minor, in comparison, and something they would work on through practice. Interview data support increased efforts within universities to increase flexibility and choice across courses and programs and provide time to address specific difficulties, experiment with different learning modes and technologies, assessment choices and timing. Deep learning could be a central focus of support initiatives with sufficient flexibility for students to spend greater time in selected areas of learning and support provision to explore their own learning strengths and weaknesses.

\footnotetext{
${ }^{2}$ Australian Technical and Further Education (TAFE) are State and Commonwealth funded institutions offering an array of post-school offerings predominately providing students with trade or technical qualifications.
} 


\section{Limitations and Implications for Future Work}

Interview data presented here represent the views of a small sample of students who self-identified with difficulties in the areas of learning, planning and organisation and/ or social communication, in response to an online request for volunteers. The final sample came only from teacher education students, did not represent the range of hidden disabilities known to exist in the university and did not include students with documented support requirements nor students who were failing or not coping with their studies. Sample limitations reflect recruitment and data collection methods, which were restricted due to the piloting nature of this study. Larger studies with comprehensive sampling procedures will be necessary to capture the experiences of the range of students with hidden disabilities. Data presented, however, do begin to demonstrate the strengths, gaps and opportunities of equity strategies implemented in the university and assist in guiding future research and practice.

\section{Discussion}

Students with hidden disabilities require differing and targeted supports but this study found that many do not want to seek specialised disability services to access these supports. Students reported that the most effective supports came from friends and family. Reliance on family, poses difficulties for many including international students and those from rural and remote areas who do not have easy access to their family. Universities may be able to assist students, however with additional avenues and skills for building and connecting support networks during their studies. While the first year program assisted some students to connect with other students, some students struggled in the group sessions or could not connect effectively. It should be noted that student evaluations of universally provided 
supports may not always identify the issues of students with hidden difficulties as the aggregated data may not be sensitive to the difficulties of those outside the group norms. Consideration of how evaluation methods and group programs may be tailored to different student requirements remains a challenge without specific Disabilities Service input.

The case study lends support to the contention that increased funding for embedded supports are warranted to support higher education students with hidden disabilities (see, for example, Denhart, 2008; Gale, 2002, Getzel, 2008). Gale (2000) contends universities have failed to keep pace with the changing needs of their student population, and university teaching staff generally have little understanding of the nature and impact of cognitive difficulties on learners (Heubeck \& Latimer, 2002; Noble \& Mullins, 1999; Ryan \& Brown, 2005). While interview data indicate that many education lecturers and tutors in University X were very supportive and flexible with students, it was consistently reported that this was limited to specific lecturers and tutors. Despite efforts there remain barriers to providing the discipline-specific supports students may require during their study. As reported by Goode (2007), workload, motivation issues, and internal support for teaching staff to alter teaching methods that proactively support students experiencing difficulties continue to present as barriers in University X. Professional development provided to University X staff through the university’s training institute and awareness training programs of the Disabilities Service covered both universal and differentiated supports for students with disabilities. The sessions, however, were reported to primarily attract staff already familiar and motivated by the issues. Methods for supporting all teaching and academic staff to engage with this knowledgebase and develop teaching goals that support this broader range of students remains a challenge. 
The Disabilities Service also developed procedures and guidelines to guide program development across the university. Some environments, however, were reported to be beyond the scope of the service. Professional registration bodies, for example, accredit certain programs and it can be difficult for some students to meet all of the registration requirements. University $\mathrm{X}$ was exploring these issues and while efforts were made to create optimum learning environments for different students with verified disabilities, staff reported that these barriers continued to block effective adjustments within some learning environments.

Adjustment to program and course delivery and assessment can only be made once the essential elements of the program/course are specified. Where group work, for example, is an essential element of a course, individualised assessment may not be a valid adjustment for a student experiencing social difficulties. For a course where group work is used only as a means for accessing information, however, the choice to work independently can provide a valid alternative to group work. The extraction of essential elements in programs and courses can prove challenging for university staff. Rigidity and flexibility across different disciplines and registration bodies accrediting programs and the experience and expertise of course convenors in identifying and articulating core content and essential processes still requires addressing at University X (see, for example, Ryan, 2011). This may be difficult to achieve while the differentiated approach to disability remains dominant.

Deep learning was clearly valued by many of the students who persisted in their studies despite barriers. Many achieved this by sacrificing other aspects of their lives, particularly social activities. There may be benefits to students who experience certain hidden disabilities if universities considered the extra time these students may require for deep learning along with the extra time required for accessing specialised 
supports and mastering the technologies that could support academic success. The assimilation, application, and generation of cutting edge theory and research within a chosen area of specialisation, represents the pinnacle of university learning. Different students take different paths and different timelines to pursue their learning goals and equitable universities are those that provide flexible learning opportunities to all students across the breadth of courses. Universal lifting of some of the artificially imposed time constraints across higher education systems may reduce stress related illness reported by some staff and students and permit deeper exploration of discipline areas and/or learning strategies alongside a greater emphasis on deep as opposed assessment survival approaches to learning.

The case study also raises questions about whether students with hidden disabilities should be required, as adult learners, to seek documentation from a medical or paramedical practitioner for the purpose of requesting reasonable adjustments. Can universities provide targeted supports for this diverse student group within the generic university system? Flexibility and choice within programs should reduce a student's need to request further adjustments, but where adjustments are reasonable and involve the same quality of deep learning can we trust and support students to develop self-knowledge and use this for requesting their own adjustments? Self-disclosure of a disability is a very personal decision and students with hidden disabilities often have developed strategies for dealing with a range of community responses to their difficulties. Whether diagnostic documentation should be necessary to obtain more targeted services could be investigated at this and other universities given the stigmatisation and possible assault to self-perceptions that can be attached to this process for some students (see Pliner, 1999). 
Further research is required to determine the extent to which students who attain a diagnostic report from a practitioner and share assessment details with support people such as DSOs, lecturers and friends are advantaged relative to students with minimal information on their difficulties or who choose not to disclose a diagnosis to attain supports. There are major equity issues to address if quality assessments are found to be necessary for adequate support of students with hidden disabilities in Australian universities. There are difficulties attaining these detailed assessments and difficulties faced by students without family or professional support representing those least likely to apply and/or persist with higher education. The linking of legal obligations and funding of support services (e.g. Commonwealth of Australia, 2010) on the basis of detailed diagnostic information requires consideration.

Universal design of supports, programs and courses aims to provide greater access to larger numbers of students with hidden disabilities; however, more work is required to ensure these are flexible and broad enough in scope to target the many different issues experienced by students.

Finally, universities may benefit from finding and evaluating effective methods for empowering and supporting students to develop an understanding of their personal learning strengths and limitations, self-advocate and to develop and access the supports they require to succeed in higher education and beyond. 


\section{References}

American Psychiatric Association. (2000). Diagnostic and statistical manual of mental disorders (4th ed. Text revision). Washington, DC: Author.

Baeten, M., Kyndt, E., Struyven, K., \& Dochy, F. (2010). Using student-centred learning environments to stimulate deep approaches to learning: Factors encouraging or discouraging their effectiveness. Educational Research Review, 5(3), 243-260. doi: 10.1016/j.edurev.2010.06.001

Bebko, J. M., \& Ricciuti, C. (2000). Executive functioning and memory strategy use in children with autism: The influence of time constraints on spontaneous rehearsal. Autism: The International Journal of Research and Practice, 4(3), 299 - 320. doi: 10.1177/1362361300004003006

Benshalom, D. (2003). Memory in autism: review and synthesis. Cortex, 39, 1129 1138.

Boone, K. B., Swerdloff, R. S., Miller, B. L., Geschwind, D. H., Razani, J., Lee, A., .. . Paul, L. (2001). Neuropsychological profiles of adults with Klinefelter syndrome. Journal of the International Neuropsychological Society, 7, 446 456.

Bowler, D. M., Gardiner, J. M., \& Grice, S. (2000). Episodic memory and remembering in adults with Asperger syndrome. Journal of Autism and Developmental Disorders, 30, 295 - 304. doi: 10.1023/A:1005575216176

Bryan, E., \& Simmons, L. A. (2009). Family involvement: Impacts on postsecondary educational success for first-generation Appalachian college students. Journal of College Student Development, 50(4), 391-406. Retrieved from http://search.proquest.com/docview/61841096?accountid=14723; http://muse.jhu.edu/login?uri=/journals/journal_of_college_student_developm ent/v050/50.4.bryan.pdf

Commonwealth of Australia. (2009). Transforming Australia's Higher Education System. Retrieved from http://www.deewr.gov.au/HigherEducation/Documents/PDF/Additional\%20R eport\%20-\%20Transforming\%20Aus\%20Higher\%20ED_webaw.pdf

Commonwealth of Australia (2006). Disability Standards for Education plus Guidance Notes. Retrieved 20th October from http://www.deewr.gov.au/Schooling/Programs/Documents/Disability_Standar ds_for_Education_2005_pdf.pdf

Commonwealth of Australia. (2010). Higher Education Support Act 2003. Other Grants Guidelines (Education) Retrieved December 9, 2011, from http://www.comlaw.gov.au/Details/F2010L01076/Html/Text\#_Toc258318309

Crane, L., Goddard, L., \& Pring, L. (2009). Sensory processing in adults with autism spectrum disorders. Autism 13, 215-228. doi: 10.1177/1362361309103794

Denhart, H. (2008). Deconstructing barriers, perceptions of students labeled with learning disabilities in higher education. Journal of Learning Disabilities, 41(6), 483 - 497.

Department of Education Employment and Workplace Relations. (2008). Publications - Higher Education Statistics Collections Retrieved 18th August, 2009, from http://www.dest.gov.au/sectors/higher_education/publications_resources/statis tics/publications_higher_education_statistics_collections.htm\#studpubs

Department of Education Employment and Workplace Relations. (2010). Higher Education Support Act 2003 - Other Grants Guidelines (Education) 2010 
(DEEWR), Retrieved 23 November, 2011, from

http://www.comlaw.gov.au/Details/F2010L01076

Dickson, E. (2007). Disability Standards for Education and Reasonable Adjustment in the Tertiary Education Sector. Australia and New Zealand Journal of Law and Education, 12(2), 25 - 41.

Fayyad, J., De Graaf, R., J., K., Alonso, M., Angermeyer, M., Demyttenaere, K., . . . Jin, R. (2007). Cross-national prevalence and correlates of adult attentiodeficit hyperactivity disorder. British Journal of Psychiatry, 190, 402-409.

Gale, T. (2000). (Dis)ordering teacher education: From problem students to problembased learning. Journal of Education for Teaching, 26(2), 129-138. doi: $10.1080 / 02607470050127045$

Gale, T. (2002). Degrees of difficulty: an ecological account of learning in Australian higher education. Studies in Higher Education, 27(1), 65-78. doi: 10.1080/0307507012009937 7

Getzel, E. E. (2008). Addressing the persistence and retention of students with disabilities in higher education: Incorporating key strategies and supports on campus. Exceptionality, 16, 207 - 219.

Goode, J. (2007). 'Managing' disability: early experiences of university students with disabilities. Disability and Society, 22(1), 35 - 48.

Green, D., Baird, G., Barnett, A. L., Henderson, L., Huber, J., \& Henderson, S. E. (2002). The severity and nature of motor impairment in Asperger's syndrome: a comparison with Specific Developmental Disorder of Motor Function. The Journal of Child Psychology and Psychiatry, 43(5), 655-668. doi: 10.1111/1469-7610.00054

Gupta, R. (2010). Specific Cognitive Deficits in ADHD: A Diagnostic Concern in Differential Diagnosis. Journal of child and family studies, 19(6), 778-786. doi: 10.1007/s10826-010-9369-4

Haggis, T. (2006). Pedagogies for diversity: retaining critical challenge amidst fears of 'dumbing down'. Studies in Higher Education, 31(5), 521-535.

Happé, F. (2000). Parts and wholes, meaning and minds: Central coherence and its relation to theory of mind. In S. Baron-Cohen, H. Tager-Flusberg \& D. Cohen (Eds.), Understanding other minds: Perspectives from developmental cognitive neuroscience (2nd ed., pp. 203-221). Oxford: Oxford University Press.

Hare, D. J., Mellor, C., \& Azmi, S. (2007). Episodic memory in adults with autistic spectrum disorders: Recall for self versus other-experienced events. Research in Developmental Disabilities, 28, 317-329.

Harrison, A. G., Nichols, E., \& Larochette, A.-C. (2009). Investigating the quality of learning disability documentation provided by students in higher education. Canadian Journal of School Psychology, 23(2), 161 - 174.

Hartman-Hall, H., \& Haaga, D. A. F. (2002). College students' willingness to seek help for their learning disabilities. Learning Disability Quarterly, 25, 263-274.

Heubeck, B. G., \& Latimer, S. (2002). Ability and achievement characteristics of Australian university students with self-reported specific learning disabilities. Higher Education Research and Development, 21(3), 273 - 287. doi: 10.1080/0729436022000020779

Ingram, A., Pianu, E., \& Welsh, R. (2007). Supporting dyslexic Scottish university hospitality students: positive actions for the future? International Journal of Contemporary Hospitality Management, 19(7), 606 - 611. 
Johnson, G., Zascavage, V., \& Gerber, S. (2008). Junior college experience and students with learning disabilities: Implications for success at the four year university. College Student Journal, 42(4), 1162 - 1168.

Kaye, S., Darke, S., \& Torok, M. (2013). Attention deficit hyperactivity disorder (ADHD) among illicit psychostimulant users: a hidden disorder? Addiction, 108(5), 923-31. doi:10.1111/add.12086

Kirby, A., Sugden, D., Beveridge, S., \& Edwards, L. (2008). Developmental coordination disorder (DCD) in adolescents and adults in further and higher education. Journal of Research in Special Educational Needs, 8(3), 120 - 131.

Kirby, J. R., Silvestri, R., Allingham, B. H., Parrila, R., \& La Fave, C. B. (2008). Learning strategies and study approaches of postsecondary students with dyslexia. Journal of Learning Disabilities, 41(1), 85 - 96.

Kuh, G. D., Kinzie, J., Schuh, J. H., \& Whitt, E. J. (2005). Never let it rest: lessons about student success from high-performing colleges and universities. Change, 37(4), $44-51$.

Landerl, K., \& Moll, K. (2010). Comorbidity of learning disorders: prevalence and familial transmission. Journal of Child Psychology and Psychiatry, 51(3), 287-294.

Laskera, A. G., Mazzocco, M. M., \& Zee, D. S. (2007). Ocular motor indicators of executive dysfunction in fragile $\mathrm{X}$ and Turner syndromes. Brain and Cognition, 63(3), 203-220.

MacLeod, A., \& Green, S. (2009). Beyond the books: case study of a collaborative and holistic support model for university students with Asperger syndrome. Studies in Higher Education, 33(5), 1-16.

May, A. L., \& Stone, C. A. (2010). Stereotypes of individuals with learning disabilities: views of college students with and without learning disabilities. Journal of Learning Disabilities, 43(6), 483-499.

Noble, A. \& Mullins, G. (1999). Valuing diversity: Teaching students with a disability. Paper presented at the Higher Education Research and Development Society of Australia Annual International Conference, Melbourne.

Perdigones, A., Garcia, J. L., Valino, V., \& Raposo, C. (2009). Assessing heterogeneous student bodies using a methodology that encourages the acquisition of skills valued by employers. Assessment and Evaluation in Higher Education, 34(4), 389 - 400.

Pliner, S. M. (1999). Listening to the learning disabled: Self-perceptions of learning disabled identity among college students. Doctor of Education, University of Massachusetts, Amherst.

Prevatt, F., Welles, T. L., Li, H., \& Proctor, B. (2010). The contribution of memory and anxiety to the math performance of college students with learning disabilities. Learning Disabilities Research and Practice, 25(1), 39-47.

Prowse, S. (2009). Institutional construction of disabled students. Journal of Higher Education Policy and Management, 31(1), 89-96.

Rasher, S. (2008). Disorderly Conduct. The Chronicle of Higher Education, 55(7), B. 24. Retrieved from

Robinson, G. L. (2002). Assessment of learning disabilities: The complexity of causes and consequences. Australian Journal of Learning Disabilities, 7(1), 29-39.

Rose, D. \& Meyer, A. (2002). Teaching every student in the digital age: Universal design for learning. Alexandria, VA: Association for Supervision and Curriculum Development. 
Ryan, J. (2007). Learning disabilities in Australian universities: hidden, ignored, and unwelcome. Journal of Learning Disabilities, 40(5), 436-442.

Ryan, J. (2011). Access and participation in higher education of students with disabilities: access to what? Australian Educational Researcher, 38, 73-93.

Ryan, J. \& Brown, M. (2005). 'Just of them to learn better': The impact of learning difficulties at university. Australian Journal of Learning Disabilities, 10(1), 19-24. doi: 10.1080/19404150509546782

Smith, C. P. (2007). Support services for students with Asperger's Syndrome in higher education. College Student Journal, 41(3), 515 - 531.

Smith, S., Carroll, A., \& Elkins, J. (1999). University students with learning disabilities: results of a national survey. Australian Journal of Learning Disabilities, 4(1), 18 - 30.

Stokes, L. (2003). Gatherings as a Retention Strategy. ABNF Journal, 14(4), 80-82.

Tinklin, T., Riddell, S., \& Wilson, A. (2004). Policy and provision for disabled students in higher education in Scotland and England: the current state of play. Studies in Higher Education, 29(5), 637-657.

Woodcock, S., \& Vialle, W. (2011). Are we exacerbating students' learning disabilities? An investigation of preservice teachers' attributions of the educational outcomes of students with learning disabilities. Annals of Dyslexia, 61(2), 223-241. doi: 10.1007/s11881-011-0058-9 